\title{
TITLE:
}

\section{OOZOOID FORMATION IN THE ASCIDIAN BOTRYLLOIDES VIOLACEUS}

$\operatorname{AUTHOR(S):~}$

Takeuchi, Kiyoshi

CITATION:

Takeuchi, Kiyoshi. OOZOOID FORMATION IN THE ASCIDIAN

BOTRYLLOIDES VIOLACEUS. PUBLICATIONS OF THE SETO MARINE BIOLOGICAL LABORATORY 1980, 25(1-4): 1-5

\section{ISSUE DATE:}

1980-02-29

URL:

http://hdl.handle.net/2433/175997

RIGHT: 


\title{
OOZOOID FORMATION IN THE ASCIDIAN \\ BOTRYLLOIDES VIOLACEUS
}

\author{
KIYoshI TAKEUCHI' \\ Zoological Institute, Faculty of Science, Hokkaido University, Sapporo, Japan
}

With Table 1 and Plates I-II

\section{Introduction}

To date many studies have been carried out on the development of botryllid ascidians, including asexual reproduction (Berrill, 1941; Oka and Watanabe, 1957, 1959) and colony specificity (Oka and Watanabe, 1960). Berrill (1947) also, described the mode of oozooid formation and developmental cycle in Botrylloides leachi and B. diegense to compare them with those in Botryllus.

The above mentioned studies show the mode of oozooid formation of the subfamily Botryllinae varies with genus or species.

In the present paper, the time schedule of tadpole formation and oozooid formation in Botrylloides violaceus are described on the basis of observations on the living organisms and histological specimens.

\section{Material and Methods}

Adult colonies of Botrylloides violaceus Oka, which are common in the low intertidal zone of Oshoro Bay, Hokkaido, were collected monthly from July to September (cf. Millar, 1958). In July, mature colonies were removed from the rocks by a steel spatula and cultured in an aquarium. The colonies were dark red-brown and each system consisted of seven to five zooids. To facilitate handling, the colonies were attached to glass plates (Oka and Usui, 1944) and they were cultured in an aerated aquarium. The colonies firmly adhered to the plates within 3-4 days. Free-swimming tadpole larvae from mature colonies were collected with a pipette and they were transferred to a finger bowl of sea water in which glass plates were submerged. The larvae which had metamorphosed on the glass plates were introduced into other aquaira containing fresh aerated sea-water. The sea water was replaced every two or four days. Colonies and tadpole larvae were reared at $16-23^{\circ} \mathrm{C}$ (sea water temperature of Oshoro Bay).

Tadpole larvae, oozooids and colonies were fixed in Bouin's fluid and embedded in paraffin for histological studies. Serial sections of $7-9 \mu$ were made and they were

1) Present address: Biochemical Laboratory, The Institute of Low Temperature Science, Hokkaido University, Sapporo, Japan.

Publ. Seto Mar. Biol. Lab., XXV(1/4), 1-5, $1980 . \quad$ (Article 1) 
stained with Delafield's hematoxylin and eosin.

Since a complete redescription of the present species is given by Tokioka (1953), based on specimens collected from Sagami Bay, a middle part of Honshu, no taxonomic description is given here.

\section{Results}

1. Embryonic Development

The early embryonic development of $B$. violaceus is essentially same as those of Botrylloides leachi and B. diegense (Berrill, 1947).

In the present study, embryos of various stages from $0.2 \mathrm{~mm}$ to $1.5 \mathrm{~mm}$ in diameter (Plate I, Fig. 1) were able to be observed in a single colony. The early development of the embryo, as well as the development of incubatory pouch, were essentially same as described for Botrylloides leachi by Berrill (1947).

The incubatory pouch, which contains a developing embryo, was connected by a vascularized peduncle to the parent zooid. As the embryo developed, the blood flow between the parent zooid and pouch became reduced. Parent zooids started to regress when the connection between zooid and test matrix became loose. Within one or two days (Stage I), a tail developed in the embryo, and the blood flow became reduced in the vascular system as well as in the vascularized peduncles. By this stage ampullae had developed at the periphery of the colony.

Table 1. Time schedule of oozooid formation

\begin{tabular}{|c|c|}
\hline Stage & Embryonic development \\
\hline \multirow{3}{*}{$\begin{array}{c}\mathbf{I} \\
(1-2 \text { days })\end{array}$} & $\begin{array}{l}\text { Early stage embryo in incubatory pouch. } \\
\text { Pronounced development of tail and trunk in embryo. }\end{array}$ \\
\hline & $\begin{array}{l}\text { (Condition of colony: beginning of degeneration of parent zooids; blood } \\
\text { flow between parent zooids and incubatory pouches becomes slow.) }\end{array}$ \\
\hline & $\begin{array}{l}\text { (Condition of colony: prominent degeneration of parent zooids; blood flow } \\
\text { between parent zooids and incubatory pouches stops entirely.) }\end{array}$ \\
\hline $\begin{array}{l}\text { II } \\
(1-2 \text { days })\end{array}$ & Appearance of the first free-swimming tadpole larva from incubatory pouch. \\
\hline III & Metamorphosis: attachment of tadpole larva to substratum. \\
\hline (1-24 hours) & Heart-beat begins. \\
\hline $\begin{array}{l}\text { IV } \\
(1-2 \text { days })\end{array}$ & $\begin{array}{l}\text { Nonfunctional atrial and branchial apertures appear, differentiation of the } \\
\text { branchial sac, imperfect digestive tract. } \\
\text { Appearance of first blastozooids as small vesicles. }\end{array}$ \\
\hline $\begin{array}{c}\mathrm{V} \\
(1-2 \text { days })\end{array}$ & $\begin{array}{l}\text { Elongation of active atrial and branchial aperture, beginning of feeding, } \\
\text { active circulation of blood flow in the vascular system. } \\
\text { Internal organs are also functional. }\end{array}$ \\
\hline $\begin{array}{l}\text { VI } \\
(4-7 \text { days })\end{array}$ & Appearance of first blastozooids on both sides of oozooid. \\
\hline $\begin{array}{c}\text { VII } \\
(3-4 \text { days })\end{array}$ & $\begin{array}{l}\text { Degeneration of oozooid. } \\
\text { The first blastozooid becomes functional. }\end{array}$ \\
\hline
\end{tabular}


After a few more days, tadpole larvae (Plate I, Fig. 2) began to swim out of the incubatory pouches (cf. Berrill, 1947), at which time the blood flow between parent zooid and incubatory pouch ceased. The regression of the zooid was a prominent feature of the colony at this time.

\section{Metamorphosis}

The active free-swimming period of tadpoles, measuring about 2--2.8 $\mathrm{mm}$ in length (cf. Tokioka, 1953), varied from 1 to 24 hours in the present study (cf. Berrill, 1947). After the free-swimming stage, the larvae became attached to the glass plates by their elongated ampullae (Stage III). The trunk region of the tadpole at this stage contained the endostyle, protostigmata and digestive tract (Plate II, Fig. 3). Three small conical adhesive organs were triangularly arranged on the apex of the trunk.

The beginning of metamorphosis is characterized by resorption of the tail and expansion of anterior trunk region (Plate II, Fig. 4) which contains about twenty elongated ampullae for attachment.

\section{Development of oozooid}

It takes one or two days from the attachment to the formation of a functional zooid. In this stage (Stage IV), the differentiation of atrial and branchial apertures and that of the branchial sac are advanced, but the structure of the digestive tract looks rather simple (Plate II, Fig. 5). Each of the first blastozooids is recognizable as a small vesicle in the posterior part of the oozooid. At this time, the heart-beat and developing ampullae are observed. The tail remains partly at the base of the body (Plate I, Fig. 3).

In one or two days, the branchial and atrial apertures become functional and feeding begins (Stage V). In this stage, the branchial sac, stomach and intestine are recognizable as highly developed organs in the sections (Plate II, Figs. 6 \& 7).

Four to seven days after metamorphosis (Stage VI), blastozooids appear at the postero-left and right sides (Plate I, Fig. 4; Plate II, Figs. $7 \& 8$ ). The oozooid were active for about 7 to 10 days and then degenerated when the first blastozooid became functional (Stage VII). In the present study, the first blastozooid did not always form a system with the oozooid. Usually the first blastozooid became functional as the degeneration of oozooid began (Plate II, Fig. 1).

\section{Discussion}

The present observation is consistent with Berrill's description (1947) in many respects, although some new evidences were added. The time schedule of organ differentiation in oozooid is present for the first time in this study.

As for the liberation of the larvae, Berrill (1947) describes, "rupture of the external wall of the brood pouch liberating the tadpole directly into the common cloacal cavity appears to be the usual method employed", but in the present species the free-swimming larvae were liberated outside the colony directly from the top of the incubatory pouch. At this stage, the test matrix became loose and the degeneration of zooids became apparent.

It is known that the oozooids of Botrylloides leachi survive in an active condition for 
about a week (Berrill, 1947), and that those of Symplegma reptans 30 days (Sugimoto and Nakauchi, 1974). In this study the oozooids of Botrylloides violaceus was found to survive in an active condition for about 10 days.

\section{Summary}

1. The time schedule of oozooid formation in Botrylloides violaceus was made on the observations of living animals and on the histological examination.

2. Tadpole larvae swim out from the incubatory pouch without rupture of its external wall.

3. It takes at least one or two days from the attachment of larvae to the appearance of functional zooids.

4. The oozooids were active for about 10 days.

\section{Acknowledgements}

I am very grateful to Professor M. Nakauchi for his helpful guidance and reading the manuscript. Sincere thanks are also due to Prof. F. Iwata and Mr. K. Shinta for their encouragments.

\section{REFERENCES}

Berrill, N. J. 1941. The development of the bud in Botryllus. Biol. Bull., 80; 169-184.

1947. The developmental cycle of Botrylloides. Quart. J. Microscop. Sci., 88; 393-407.

Garstang, S.P. and W. Garstang, 1928. On the development of Botrylloides. Quart. J. Microscop. Sci., $72 ; 1-49$.

Izzard, C.S. 1973. Development of polarity and bilateral asymmetry in the palleal bud of Botryllus schlosseri (Pallas). J. Morph., 139; 1-26.

Milkman, R. 1967. Genetic and developmental studies on Botryllus schlosseri. Biol. Bull., 132; 229-243.

Millar, R. H. 1958. The breeding season of some littoral ascidian in Scottish waters. J. mar. biol. Ass. U.K., 37; 649-652.

Mukai, H. 1974. A histological study on the degeneration of zooids in a compound ascidian, Botryllus primigenus. (in Japanese). Zool. Mag., 83; 18-23.

Oka, H. and M. Usui, 1944. On the growth and propagation of the colonies in Polycitor mutabilis (ascidiae compositae). Sci. Rep. Tokyo Bunrika Daigaku, Sec. B; $2 y-53$.

Oka, H. and H. Watanabe, 1957. Vascular budding; a new type of budding in Botryllus. Biol. Bull., $112 ; 225-240$.

1959. Vascular budding in Botrylloides. Biol. Bull., $117 ; 340-346$.

1960. Problems of colony-specificity in compound ascidian. Bull. Mar. Biol. Stat. Asamushi, Tohoku Dniv., 10; 15y-155.

Sugimoto, K. and M. Nakauchi, 1974. Budding, sexual reproduction, and degeneration in the colonial ascidian, Symplegma reptans. Biol. Bull., 147; 213-226.

Tokioak, T. 1953. Ascidians of Sagami Bay. Iwanami-shoten, Tokyo. 


\section{EXPLANATION OF PLATES I-II}

Plate $\mathbf{I}$

Fig. 1. Various stages of embryos.

Fig. 2. Stage II; Free-swimming tadpole larva.

Fig. 3. Stage IV; Oozooid about two days after metamorphosis. Atrial and branchial apertures are recognizable.

Fig. 4. Stage V-VI; Oozooid about 8 days after metamorphosis, with two growing blastozooids.

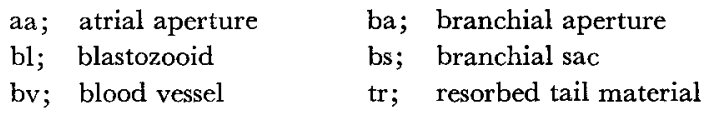

\section{Plate II}

Fig. 1. Cross section of an adult blastozooid, showing the position of gonad, branchial cavity and peribranchial cavity.

Fig. 2. Almost median cross section of incubatory pouch. The embryo has a coiled tail around larval trunk and adult organ rudiments.

Fig. 3. Longitudinal section of a free-swimming tadpole larva.

Fig. 4. Cross section of an oozooid about 10-20 hours after beginning of metamorphosis, showing most of notochordal cells passed from a sheath into body cavity of trunk.

Fig. 5. Stage IV: Longitudinal section of an oozooid.

Fig. 6. Stage IV-V: Cross section of an oozooid, showing the two blastozooids and highly organized adult organ such as stomach, intestine. Prominent blood vessels exists in the test matrix.

Fig. 7. Stage V-VI: Cross section of posterior part of an oozooid.

Fig. 8. Stage VI: Longitudinal section of an oozooid.

aa; atrial aperture
ba; branchial aperture
bl; blastozooid
bv; blood vessel
en; endostyle
h; heart
n; notochord
nt; notochord and neural tube
o; oocyte
pc; peribranchial cavity
p. stg; protostigmata
stg; stigmata

am; ampulla

bc; branchial cavity

bs; branchial sac

$\mathrm{dg}$; digestive tract

es; esophagus

in; intestine

nc; notochordal cell

pv; peduncular vessel

pe; placental epithelium

st; stomach

t; testis

tr; tail resorbed 
Publ. Seto Mar. Biol. Lab., XXV (1/4), $1980 . \quad$ Plate I

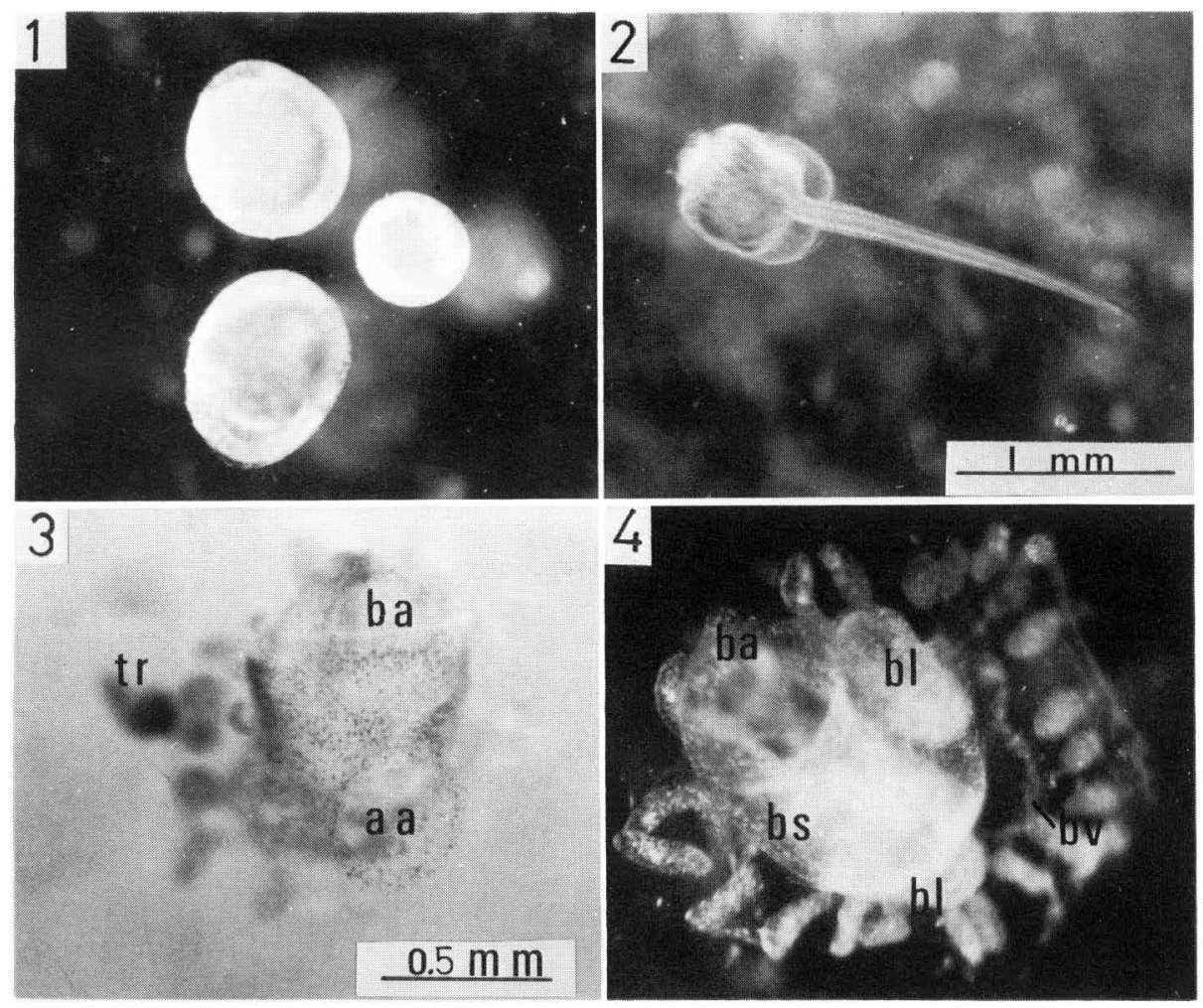

K. Takeuchi: Oozooid Formation in Ascidian 

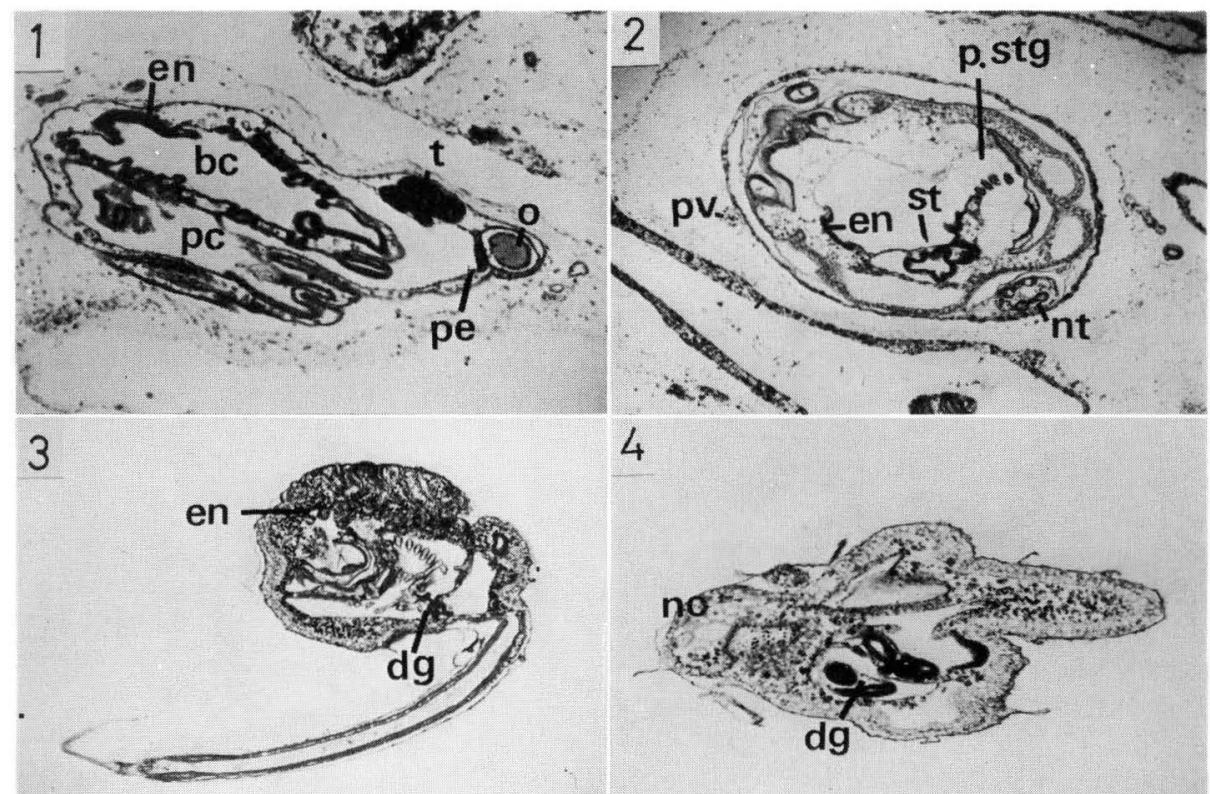

5

6
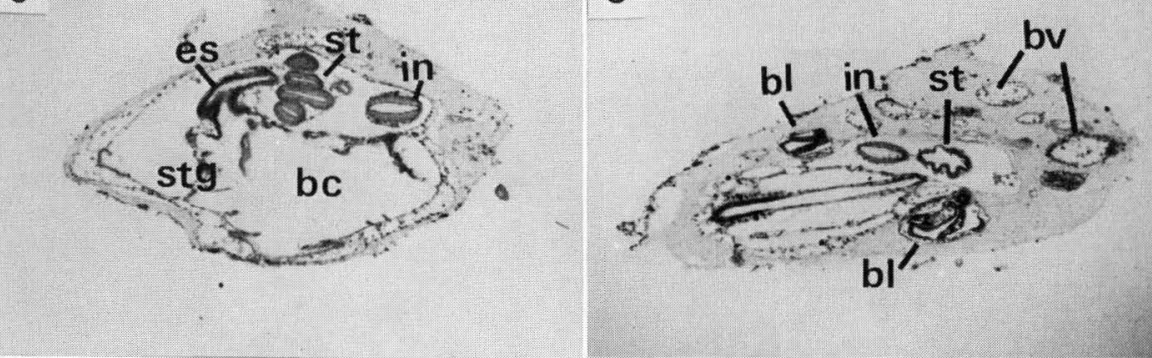

\section{7}

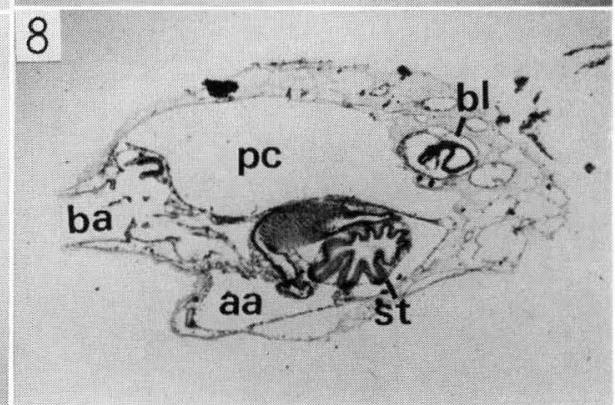

K. Takeuchi: Oozooid Formation in Ascidian 